\title{
ACEITABILIDADE DE GELÉIAS CONVENCIONAL E LIGHT DE ABACAXI OBTIDAS DE RESÍDUOS DA AGROINDÚSTRIA
}

AMANDA FISS RODRIGUES E SILVA*

RUI CARLOS ZAMBIAZI**

\begin{abstract}
No presente estudo verificou-se a viabilidade de elaboração de geléias a partir de resíduos de polpa da casca de abacaxi, visando o aproveitamento parcial dos resíduos de abacaxi gerados pela agroindústria. A polpa aderida às cascas, remanescente do descasque do abacaxi, foi extraída e utilizada na elaboração de geléias convencional e light de acordo com procedimentos adotados pelas indústrias processadoras de Pelotas (Rio Grande do Sul). As geléias obtidas foram submetidas ao teste de aceitabilidade com 85 julgadores nãotreinados. Todas as geléias obtiveram média de aceitabilidade acima de 7,0, índice mínimo de aceitabilidade para produtos a serem lançados no mercado.
\end{abstract}

* Química de alimentos, Mestre em Ciência e Tecnologia Agroindustrial, Universidade Federal de Pelotas (UFPEL), Pelotas, RS (e-mail: amanda.fiss@gmail.com).

** Professor, PhD em Food and Nutritional Science, Departamento de Ciência dos Alimentos, UFPEL, Pelotas, RS (e-mail: zambiazi@ufpel.tche.br). 


\section{INTRODUÇÃO}

O abacaxizeiro (Ananás comosus $(\mathrm{L})$, planta perene que pertencente a família Bromeliaceae, compreende aproximadamente 46 gêneros e cerca de 1.700 espécies de plantas herbáceas, epíferas e terrestres (FREIMAM e SABAA-SRUR, 1996). O Brasil tem ocupado a terceira posição como produtor mundial de abacaxi, produzindo 2,9 milhões de toneladas em 61.000 hectares plantados (IBGE, 2004). A Tailândia, as Fillipinas e o Brasil concentram mais de $40 \%$ da produção mundial desse fruto (GRANADA, ZAMBIAZI e MENDONÇA, 2004). Em termos nacionais, o estado de Minas Gerais é o principal produtor (750.000 ton), seguido pela Paraíba (545.000 ton) e pelo Pará (440.000 ton) (IBGE, 2004).

Para expandir os mercados nacional e internacional de frutas frescas, o Brasil conta com o interesse do consumidor por produtos "prontos para o consumo" (GRANADA, ZAMBIAZI e MENDONÇA 2004).

A classificação do fruto do abacaxi envolve as seguintes variedades: Smooth Cayenne, Queen, Spanish e Pérola. Essa última constitui a mais cultivada no Brasil (FREIMAN e SABAA-SRUR, 1996), porém estima-se que $70 \%$ da produção mundial tenha como base a cultivar Smooth Cayenne (GONÇALVES, 2000).

A escolha da variedade de abacaxi está diretamente relacionada com o destino da produção (BARREIRO NETO e SANTOS, 1999). No Brasil, a variedade Perola é considerada insuperável para o consumo in natura devido maior suculência e sabor de sua polpa (GRANADA, 2002). No entanto, essa cultivar não é adequada para o processamento industrial. Trata-se de fruto frágil, com polpa quase branca e pouco ácida, cujo formato cônico dificulta o enlatamento. A variedade Cayenne, mais apropriada para a industrialização, apresenta forma do fruto mais adequada ao processamento, polpa mais ácida e de melhor coloração (BARREIRO NETO e SANTOS, 1999)

Na elaboração de subprodutos do abacaxi, principalmente no processamento de abacaxi em calda, ocorre grande acúmulo de cascas, centros, aparas e outras partes não utilizadas pela agroindústria. A porção comestível representa apenas $22,5 \%$ a $35 \%$ do fruto, sendo o restante descartado. Esses resíduos, principalmente de cascas, obtidos durante o descasque mecânico do fruto contém quantidade considerável de polpa aderida, que é descartada juntamente com os outros resíduos. Tais resíduos servem apenas como material base para a alimentação animal (PRADO et al, 2003), não sendo utilizados para a obtenção de subprodutos.

A região sul do estado do Rio Grande do Sul destaca-se pela tradição de suas indústrias de conservas, sendo um dos seus principais produtos oriundo do processamento de frutas em calda e geléias. A geléia consiste na cocção das frutas inteiras ou em pedaços, polpa ou suco de frutas, com açúcar e água, concentrado até se obter a consistência gelatinosa, podendo ocorrer a adição de glicose, acidulante e pectina (JACKIX, 1988).

A oferta, e também a grande procura por produtos com valores calóricos reduzidos, trouxe a preocupação de como harmonizar o prazer da doçura com a manutenção da saúde (CAMPOS e CÂNDIDO,1995). Por esse motivo, as indústrias de processamento de frutas ofertam geléias light com redução de no mínimo $25 \%$ de calorias (ANVISA, 2005). O fruto do abacaxizeiro tem sido muito utilizado para a produção de geléias devido sua acidez e sabor marcante, desejáveis para esse tipo produto.

O presente trabalho foi desenvolvido com o objetivo de aproveitar a polpa aderida à casca após o descasque mecânico do abacaxi na forma de geléias convencional e light, visando reduzir a geração de resíduos e proporcionar maior lucratividade para as agroindústrias.

\section{MATERIAL E MÉTODOS}

\subsection{MATERIAL}

Como matéria-prima utilizou-se polpa extraída de cascas de 35 abacaxis da variedade Cayenne, oriundos da região do triângulo mineiro, safra 2005. As cascas foram coletadas aleatoriamente, logo após o descasque de abacaxi destinado à elaboração de doce em calda numa agroindústria de Pelotas/RS. 
Os edulcorantes sacarina e ciclamato sob a forma sólida foram doados pela Chemax e pectina de alta metoxilação - ATM ( $150^{\circ}$ SAG) e Pectina de baixa metoxilação aminada - BTM (tipo Genu 8002) pela Cpkelco S.A. Foram empregados ainda, ácido cítrico, sacarose, glicose, cloreto de cálcio, e conservante benzoato de potássio (Merck, p.a.).

\subsubsection{Obtenção da Polpa de Resíduos}

Os abacaxis foram lavados em tanque com água clorada, contendo $5 \mathrm{ppm}$ de cloro residual livre, pesados e submetidos ao corte manual para remoção da coroa e da base. Em seguida, os frutos foram encaminhados para o setor de retirada da casca e centro realizados em equipamentos mecânicos. Os resíduos obtidos (casca, centro, aparas e coroa) foram pesados, sendo então realizada a separação das cascas.

As cascas foram submetidas à nova pesagem, seguida da lavagem com água clorada (2 ppm de cloro livre) e encaminhadas para a re-extração da polpa com auxílio de equipamento semiautomatizado, desenvolvido pela própria indústria. Após a extração da polpa aderida à casca, essa foi pesada para os cálculos de rendimento (Figura 1).

\subsubsection{Obtenção do Suco}

Triturou-se a polpa extraída da casca em triturador caseiro e efetuou-se a separação dos resíduos sólidos e do suco de abacaxi (Figura 1), usando peneiras com perfurações de 1,5 mm. O suco separado foi encaminhado para a elaboração das geléias convencional (tipo extra) e light (com redução de $30 \%$ e $50 \%$ de sacarose).

\section{FIGURA 1 - FLUXOGRAMA DA OBTENÇÃO DA POLPA E DA POLPA EXTRAÍDA DA CASCA DO ABACAXI}

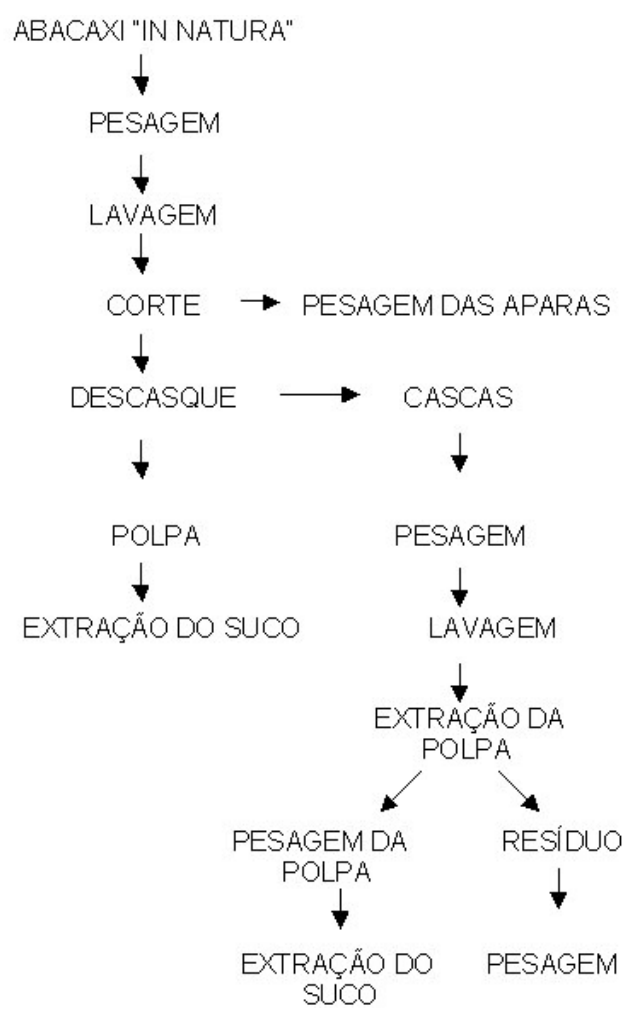




\subsubsection{Obtenção das Geléias}

Levou-se o suco para cocção em tacho aberto, no qual foram adicionados os outros ingredientes. Para a elaboração da geléia convencional $(F 1)$, inicialmente adicionou-se a sacarose (1:1, p/p em relação ao suco) juntamente com a pectina comercial de alta metoxilação - ATM (1\% p/p em relação a sacarose). Para a elaboração das geléias light com redução de $30 \%$ (F2) e $50 \%$ (F3) de açúcar foram adicionados (além da sacarose) os edulcorantes sacarina e ciclamato (1:1 p/p em relação a sacarose), juntamente com a pectina de baixa metoxilação - BTM (1,8\% p/p em relação ao açúcar) comercial do tipo Genu 8002.

Depois que as geléias atingiram $20^{\circ}$ Brix acrescentou-se a glicose $(10 \%$ p/p em relação à sacarose). Prosseguiu-se a evaporação até alcançar o teor de sólidos solúveis de $67^{\circ} \mathrm{Brix}$ para a geléia convencional e de $48^{\circ}$ Brix para as geléias light. Adicionou-se o ácido cítrico (1,5\% p/p em relação ao suco) e benzoato de sódio ( $0,05 \%$ p/p em relação ao suco) como conservante em ambas as geléias. Nas geléias light acrescentou-se cloreto de cálcio (40 mg/g de pectina BTM) para a ação sinérgica com a pectina BTM (NAGHTIGALL, 2003) (Figura 2).

\section{FIGURA 2 - FLUXOGRAMA DO PROCESSAMENTO DAS GELÉIAS DE ABACAXI}

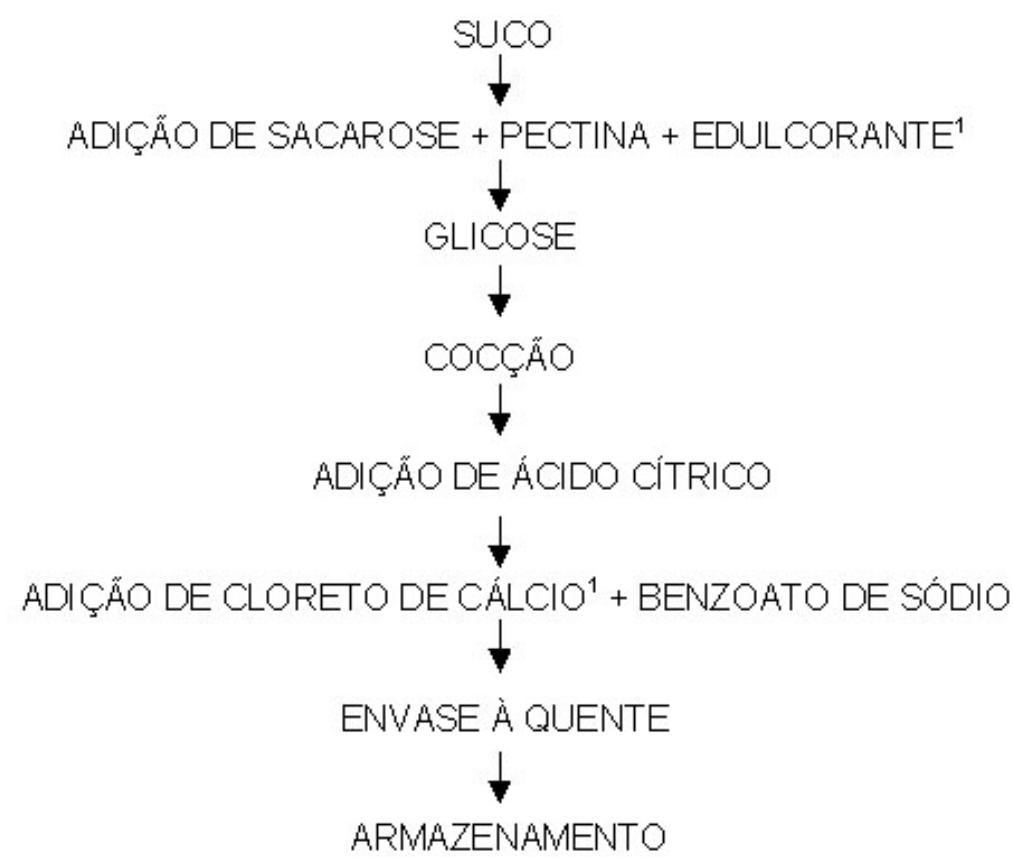

${ }^{1}$ Utilizado na formulação light

\subsubsection{Determinação de Açúcares Totais}

Realizou-se a determinação de açúcares totais nas geléias pelo método volumétrico, mediante titulação com solução de Fehling, expressos em \% de glicose (IAL, 1985).

\subsection{ANÁLISE SENSORIAL}

\subsubsection{Teste de Aceitabilidade}

O teste de aceitação foi realizado no laboratório de Análise Sensorial de Alimentos do Departamento de Ciência dos Alimentos (DCA/UFPEL). Participaram 85 julgadores não-treinados na 
faixa etária de 18 a 50 anos, escolhidos aleatoriamente, desde que gostassem de abacaxi e de geléia.

Os julgadores avaliaram o quanto gostaram ou desgostaram do produto, mediante escala hedônica de 9 pontos, ancorada nos extremos (9-1) pelos termos "gostei muitíssimo" e "desgostei muitíssimo" (GULARTE, 2001; ABNT, 1994).

Cerca de $10 \mathrm{~g}$ de geléia foi servida em recipientes brancos de porcelana a temperatura ambiente $\left( \pm 22^{\circ} \mathrm{C}\right)$. Cada amostra foi codificada com números de 3 dígitos, sendo servidas aleatoriamente aos julgadores (GULARTE, 2001; TEIXEIRA, MEINERT e BARBETTA, 1987).

Os resultados dos testes de aceitabilidade foram avaliados pela análise de variância (ANOVA), e as médias significativas pelo teste de Tukey (nível de $5 \%$ de probabilidade), utilizando-se o programa Statistica 6.0 (STATSOFT, 2000).

\section{RESULTADOS E DISCUSSÃO}

\subsection{RENDIMENTO DAS POLPAS OBTIDAS DE RESÍDUOS}

A Tabela 1 apresenta a média de peso dos abacaxis e de suas partes. Verificou-se que mais de $60 \%$ do peso total do abacaxi consiste em resíduos (centro, aparas, cascas e coroa) e que a polpa destinada para elaboração de abacaxi em calda representa apenas 39,35\%.

Dos resíduos originados durante o processo industrial para elaboração de abacaxi em calda, $31,72 \%$ são representados pela cascas. A extração da polpa aderida às cascas somou $10,54 \%$, em média, do peso total dos abacaxis.

Os dados obtidos com o presente experimento são similares aos descritos por FREIMAN e SABBASRUR (1996), que encontraram valores em torno de $72 \%$ para as partes não-comestíveis do abacaxi. Salienta-se que esses valores são muito variáveis, devido ao tamanho e peso dos abacaxis, que oscilam em função do trato cultural e da época em que o fruto é colhido (OMAR, IDRUS e RAZAK, 1978).

\section{TABELA 1 - MÉDIA DO PESO DE ABACAXI E SEUS RESÍDUOS}

\begin{tabular}{c|ccc}
\hline Parte & Peso Total (kg) & Médias (kg) & Percentual \\
\hline Abacaxi inteiro & $59,378 \pm 4,3$ & $1,696 \pm 2,4$ & $100,00 \%$ \\
Resíduos totais* & $36,013 \pm 3,8$ & $1,028 \pm 2,1$ & $60,65 \%$ \\
Polpa & $23,365 \pm 2,9$ & $0,667 \pm 1,7$ & $39,35 \%$ ** \\
Cascas + Polpa aderida & $1,836 \pm 1,3$ & $0,538 \pm 1,7$ & $31,72 \%{ }^{\star *}$ \\
Polpa extraída das cascas & $6,256 \pm 1,8$ & $0,179 \pm 0,9$ & $10,54 \% \star *$ \\
Cascas & $1,257 \pm 1,3$ & $0,359 \pm 1,5$ & $21,18 \% \star *$ \\
\hline
\end{tabular}

\pm desvio-padrão.

* Cascas, aparas, centro e coroa.

** Percentual em relação ao peso total de abacaxi.

\subsection{RESULTADO DAANÁLISE DE AÇÚCARES TOTAIS}

As formulações de geléias light (F2 e F3) apresentaram redução superior a 25\% de açúcares totais em relação à formulação convencional (F1), atendendo ao regulamento técnico da ANVISA 
(BRASIL, 1998) referente à informação nutricional complementar para serem consideradas light.

O conteúdo de açúcares totais na formulação de geléia convencional foi de 59,16\% (em \% de glicose) e na formulação de geléia light elaborada com polpa do resíduo (casca) de abacaxi (F2) de 44,06\% (redução de $25,52 \%$ em relação a formulação convencional). Já a formulação de geléia light elaborada com polpa do resíduo (casca) de abacaxi (F3) apresentou teor de açúcares de 40,06\% (redução de $32,28 \%$ em relação a formulação convencional). Esses percentuais de redução são semelhantes aos encontrados por NACHTIGALL (2003) em geléias de hibisco light (redução de 29,41\% a 33,41\%) e por GRANADA (2002), que verificou redução entre 33,80\% a 36,96\% de açúcares em geléias light de abacaxi.

\subsection{RESULTADOS DO TESTE DE ACEITABILIDADE DAS GELÉIAS}

Na Figura 3 estão apresentados os resultados do teste de aceitabilidade das geléias elaboradas a partir da polpa de resíduos, realizado com 85 julgadores oriundos da comunidade do campus universitário da UFPel.

Considerou-se a média da soma dos valores obtidos em todas as análises efetuadas com escala hedônica de 9 pontos.

\section{FIGURA 3 - PERCENTUAIS MÉDIOS DE ACEITAÇÃO DAS GELÉIAS DE ABACAXI ELABORADA A PARTIR DA POLPA DE RESÍDUO}

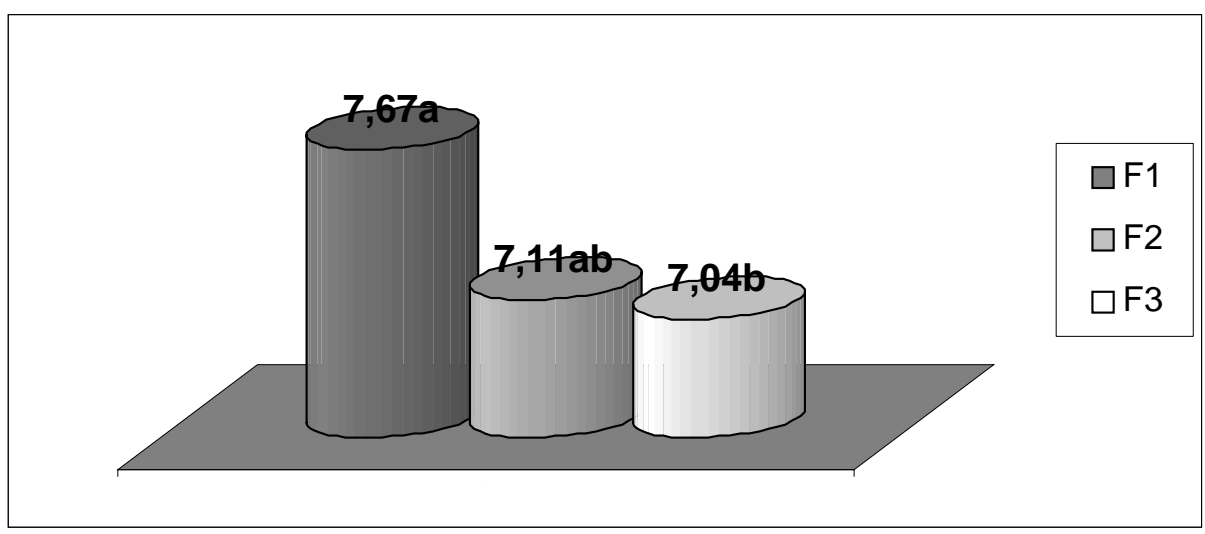

F1 = (geléia convencional elaborada com polpa do resíduo (casca) de abacaxi).

F2 = (geléia light elaborada com polpa do resíduo (casca) de abacaxi, com redução de $30 \%$ em sacarose).

F3 = (geléia light elaborada com polpa do resíduo (casca) de abacaxi, com redução de $50 \%$ em sacarose).

Segundo os resultados do teste de aceitabilidade, os julgadores manifestaram maior aceitação pela formulação convencional (F1) de abacaxi (média de 7,67). As formulações light com redução de $30 \%$ (F2) e de 50\% (F3) de açúcar obtiveram médias de 7,11 e 7,04, respectivamente. Esses resultados são semelhantes aos obtidos por GRANADA (2002), estudando geléias de abacaxi com reduzido valor calórico.

Não houve diferença significativa entre a formulação convencional de polpa de resíduo (F1) e a formulação light de polpa de resíduo com redução de $30 \%$ de sacarose (F2). No entanto, observou-se diferença significativa entre a formulação elaborada com polpa de resíduo com redução de $50 \%$ de sacarose (F3) e as demais.

Segundo comentários descritos pelos julgadores nas fichas do teste de aceitação, o ponto negativo das formulações light elaboradas com polpa do resíduo (casca) de abacaxi foi o sabor residual dos edulcorantes. Tal fato foi mais evidente na formulação com redução de $50 \%$ em sacarose (menor aceitação).

Segundo TEIXEIRA, MEINERT e BARBETTA (1987) para que determinado produto seja 
considerado aceito em termos de suas propriedades sensoriais deve alcançar índice de aceitabilidade de no mínimo $70 \%$ (média maior ou igual a 7,0). De acordo com esse critério percebe-se que todas as formulações seriam aceitas pelo mercado consumidor. No entanto, a aceitação também dependente de outros fatores como, preço, qualidade nutricional, disponibilidade e marketing (CHAVES e SPROESSER, 1993).

Verificou-se que com pouco ou nenhum valor, os resíduos de polpa gerados na industrialização do abacaxi em calda podem ser aproveitados e gerar lucro extra para as agroindústrias.

\section{CONCLUSÃO}

O resíduo proveniente da industrialização do abacaxi em calda, em especial a polpa obtida da casca, rende percentual de matéria-prima (polpa) de cerca de 10,5\% do peso do abacaxi inteiro.

Os resultados da análise sensorial indicaram que a polpa aderida na casca (resíduo) do abacaxi pode representar excelente matéria-prima para a obtenção de geléias convencional e light.

\section{ABSTRACT \\ ACCEPTABILITY OF CONVENTIONAL AND LIGHT PINEAPPLE JELLIES OBTAINED FROM AGROINDUSTRIAL RESIDUES}

In the present study the viability of jellies elaboration from pineapple pulp and rind residues was verified, aiming the partial utilization of pineapple residues generated by agro-industries. The pulp adhered to the rinds after removing the rinds, was extracted and used in the elaboration of conventional and light jellies in accordance with the procedures adopted by Pelotas (Rio Grande do Sul, Brazil) processing industries. The jellies were submitted to an acceptability test, using 85 non trained judges. All jellies reached acceptability average above 7.0 , that is the minimum index of acceptability for a product to be introduced at the market.

KEY-WORDS: PINEAPPLE; RIND RESIDUES; JELLY; ACCEPTABILITY.

\section{REFERÊNCIAS}

1 ANVISA. Agência Nacional de Vigilância Sanitária. Legislação para alimentos "light". Portaria no 27, de 13 de janeiro de 1998. Disponível em: http://www.anvisa.gov.br/alimentos/legis/especifica/index.> Acesso em: 27 de set. 2005.

2 ABNT. Associação Brasileira de Normas Técnicas. NBR 12994: métodos de avaliação sensorial de alimentos e bebidas. São Paulo, 1994.

3 BARREIRO NETO, M.; SANTOS, E.S. Abacaxicultura: contribuição tecnológica. João Pessoa: EMEPA-PB, 1999. $96 \mathrm{p}$.

4 ChAVES, J. B. P.; SPROESSER, R. L. Práticas de laboratório de análise sensorial de alimentos e bebidas. Viçosa: Imprensa Universitária UFV, 1993. 82 p.

5 CAMPOS, A. M.; CÂNDIDO, L. M. B. Formulação e avaliação físico-química e reológica de geléias de baixo teor de sólidos solúveis com diferentes adoçantes e edulcorantes. Revista Ciência e Tecnologia de Alimentos. Campinas, v. 15 , n. 3, p. 268-278, dez.1995.

6 FREIMAN, L. O; SABAA-SRUR, A. U. O. O aproveitamento dos resíduos da agroindústria do abacaxi (Ananas comosus (L) MERRIL) para a produção de Bromelina. Revista Ciência e Tecnologia de Alimentos. Campinas, v. 6, n. 3, p. 246-249, dez. 1996

7 GONÇALVES, N. B. Abacaxi pós-colheita. Brasília: Embrapa, 2000. 45 p.

8 GULARTE, M. A. Manual de análise sensorial de alimentos. Pelotas: UFPEL, 2002. 59 p.

9 GRANADA, G. G. Geléias de abacaxi com reduzido valor calórico. Pelotas, 2002. 97 p. Dissertação (Mestrado em Ciência e Tecnologia Agroindustrial, Área de concentração: Frutas e Hortaliças), Departamento de Ciência e Tecnologia Agroindústria, Universidade Federal de Pelotas. 
10 GRANADA, G. G.; ZAMBIAZI, R. C.; MENDOÇA, C. R. B. Abacaxi: produção, mercado e subprodutos. Boletim do CEPPA, Curitiba, v. 22, n.2, p.405-422, jul./dez. 2004.

11 IBGE. Instituto Brasileiro de Geografia e Estatística. Dados de safra de abacaxi no Brasil. Disponível em: <http:// www.sidra.ibge.gov.br>. Acesso em: 28 ago. 2005.

12 IAL. Instituto Adolfo Lutz. Normas analíticas do Instituto Adolfo Lutz: métodos químicos e físicos para a análise de alimentos. 2. ed. São Paulo, 1985. 371 p.

13 JACKIX, M. H. Doces, geléias e frutas em calda. São Paulo: Editora Ícone, 1988. 172 p.

14 NAGHTIGALL, A. M. Efeito dos edulcorantes sucralose e acesulfame-k em geléias light de hibisco. Pelotas, 2003. 71 f. Dissertação (Mestrado em Ciência e Tecnologia Agroindustrial), Faculdade de Agronomia, Universidade Federal de Pelotas.

15 OMAR, S; IDRUS, A. Z.; RAZAK, O. A. Extraction and activity of bromelain from pineapple. Mardi Reserch Bulletin, Malásia, v.6, n.2, p. 172-179, Feb. 1978.

16 PRADO, I. N. et al. Níveis de substituição da silagem de milho pela silagem de resíduo industrial de abacaxi sobre o desempenho de bovinos confinados. Revista Brasileira de Zootecnia, Viçosa, v. 32, n. 3, p. 737-744, 2003.

17 STATSOFT Inc. Statistica. Tulsa, 2000. Software version 6.0.

18 TEIXEIRA, E.; MEINERT, E. M.; BARBETTA, P. A. Análise sensorial de alimentos. Florianópolis: UFSC, 1987. 180 p. 